\title{
Communicative culture as a key element of future interpreter's professional training
}

\author{
K. Zavision \\ Alfred Nobel University, Dnipro \\ Corresponding author. E-mail: zavizion.katherine@gmail.com
}

Paper received 19.09.19; Accepted for publication 07.10.19.

\begin{abstract}
ttps://doi.org/10.31174/SEND-PP2019-207VII84-12
\end{abstract}
\begin{abstract}
In the XXI century translation study, pedagogy, psychology have been developing rapidly, however the problem of development future interpreter's communicative culture is still insufficiently researched. In the given research work a study of the key definitions to the notions "communication" and "culture" is offered, hence definition to the notion "interpreter's communicative culture" is presented. Further in the research work analysis of the main approaches by Ukrainian and foreign scientists to pedagogical process of forming interpreter's communicative culture is presented. The new integrated approach to forming communicative culture of future interpreters is introduced in the given paper. This approach combines key aspects of active (intensive teaching methods), profession-oriented (students' needs, interests and requirements of future profession are highly considered in the process of education), competence (the emphasis is placed on the result, rather than on the process of educational process) and cultural (beneficial interdependence of language and culture in education) approaches. Finally, various teaching tools for development future interpreter's communicative culture are represented. The research clearly shows that implementation of game technologies in educational process result in a more beneficial and effective teaching process. Analysis of the in-class experience shows that students who faced business games and other interactive activities had higher motivation to participate in the lesson and, thus, acquired new language skills, which are necessary in their future profession.
\end{abstract}

Keywords: communicative culture, interpreter, professional training, pedagogy, integrated approach.

Introduction. In the recent years our country has been facing an extremely active process of integration into European community that resulted in change of the translator's role in economic, political and social life of the nation. Nowadays demand for interpreters' professional training of is growing rapidly. Taking into consideration the above mentioned factors, universities are forced to change their approaches to preparation of future translators. It is vital to develop student's communicative culture, as the main role of an interpreter today is not to render words and phrases, but to act as a mediator between representatives of different nations. Today communication is highly influenced by culture. Even the means of communication chosen by businessmen depend upon cultural habits. Previously it was considered that in industrialized countries like the USA, Germany, France etc, people rely heavily on electronic technology, tending to use e-mails and the Internet rather than face-to-face communication. But recent research has shown that Japan, which has access to the most up-to-date technology, still relies mainly on real-life direct communication [6]. Analyzing these facts, we can come to conclusion, that determining factor for choosing means of communication is not the degree of industrialization, but historical and cultural predominance of the nation. In the process of their professional training future interpreters have to be taught, that there are cultural differences in ways of sending and retrieving messages, moreover in the content of a message itself. For instance in countries of Mediterranean region, Central and Eastern Europe, Latin America and Africa personal bonds and informal agreements are much more binding, than a signed document. Representatives of these countries tend to leave much of the information unspoken, understood from the context. In business, they pay immense attention to body language and intonation, silences and pauses. Whereas in countries of Western Europe people would expect to receive clear, specific and accurate message, they strictly observe wording of a document, being precise with every spoken or written phrase. All the above-mentioned differences should be observed and considered by a professional interpreter. It is vital for him to consider receiver's pragmatics and to adopt the message to meet his demands.

Literature review. Analysis of recent research made by national and international scholars, namely V. Burikina, N. Volkova, M. Herskovits, V. Katkova, C. Goman, shows that the problem of forming interpreter's communicative culture has not been investigated properly. First of all, we believe it is necessary to study such notions as "communication" and "culture" in general, and then to offer definition of the notion "interpreter's communicative culture". For many years the problem of effective information exchange (communication) has been studied by numerous scholars all over the world. The history of communication investigation goes back to antiquity (IV-I century BC). In that period the essence of information exchange process was identified as well as some aspects of its studying and application. Such prominent philosophers of that period as Demosthenes, Socrates, Aristotle, M. Aurelius, Cicero were working on this problem [12]. Sophists have also studied the process of information exchange. Their work was primarily aimed at development of speech pomposity, they tried to increase the influence of every word pronounced. Socrates proclaimed: "A word puts us over animals. With its help we can build cities, create laws and perceive arts". Even at that period philosophers realized the power of speech, they paid special attention to the ability of making speeches and culture of dialogue. Socrates has said: "Talk to me so that I could see you" [12].

While studying modern approaches to defining a notion "communication", we can see that according to encyclopaedia "Communication is 1) means of transporting and connection between community facilities. 2) transmitting information from one person to the other in the process of their activity" [1]. Philosophic dictionary denotes "communication (Latin communication - informing, transmitting) as a contextual aspect of social interaction. 
Actions aimed at transmitting and receiving a message. The key function of communication - reaching social unity while preserving individual features of every element [10]. Within the frameworks of our research, we offer to use the definition offered by V. Katkova: "Communication is a form of connection, stipulated by social interaction in which every participant has a specific communicative role and particular communicative skills [5].

Next we are going to study the notion "culture" and define the term "interpreter's communicative culture". A word "culture" derives from Latin «cultura» (cultivation, care, development) first meant working on the land, work of a grain grower, but later this word was used in a different, figurative meaning - knowledge, good behaviour. In modern science there are more than 200 definitions of this term, but we are going to study only those, which correspond to the topic of our investigation [12].

According to C. Goman, culture is a set of shared values that a group of people holds. Every culture has a set of rules that its members take for granted [2].

N. Mitrova gives a generalized definition of this term. She believes that culture is a combination of skills and abilities, which provide mutually beneficial communication of people and effective solving of various communicative tasks. It is composed of various psychological and ethical knowledge, skills, rules and norms of communication, general education, ability to think positively and finding ways to resolve different problems [8].

W. Sumner considers that culture is a level of development acquired in any field of humans activity [11]. M. Herskovits believes that culture is a combination of behaviour and way of thinking that is typical for a particular community [4].

Aim. The aim of the research is to present the definition to the notion "interpreter's communicative culture" as well as to analyze the existing approaches to interpreter's communicative culture formation and introduce new integrated pedagogical approach to forming the abovementioned phenomenon.

Methods of study. Considering the aim of our paper we used the following methods of research: theoretical study of the problem, analysis of current approaches to translation/interpretation teaching methods and questioning $3^{\text {rd }}$ year students. Hence, we identified the main difficulties which face future interpreters in the process of their education, and offered a way to overcome the abovementioned troubles while forming future interpreter's culture.

Results and discussions. Considering the main definitions offered by Ukrainian and foreign scholars in our research we are going to use the following definition: interpreter's communicative culture is a structured functional combination of person's knowledge, skills and abilities, which enables him to reach sociocommunicative goals in the process of his professional activity.

Communication culture of people in different situations is based on certain rules, which have been developed by their society for many years. These rules define forms of interaction accepted in a particular society and are called etiquette. It embraces both technical aspects of communication, i.e. rules of behaviour and principles which should be followed, otherwise it would cause blame or even punishment. Numerous rules of etiquette have become integral elements of communication culture. Thus, taking into consideration the above mentioned facts, we can say that forming future interpreter's communicative culture is a vital aspect in his professional training.

Having defined the notion 'interpreter's communicative culture" it is worth stating which approach to forming this culture is the most effective. Within the frameworks of our investigation we offer to use the classification of approaches to teaching foreign languages published by $\mathrm{S}$. Nikolaeva [9]. The author divides approaches as to the type of psychological effect, as to the object of study and as to the method of teaching.

While investigating psychological aspect of studying foreign languages, S.Nikolaeva differentiates behaviouristic, inductive-conscious, cognitive and complex approaches [9]. In behaviouristic approach she offers to evaluate the development level of student's automatic reactions to words and phrases read or heard in foreign language. If choosing inductive-conscious approach, it is necessary to use intensive method of teaching. First students use a particular phrase or grammatical phenomenon and only after that they realize models and rules of using it. Cognitive approach presumes that students learn grammatical and lexical rules first and then use them in their speech. Whereas in complex approach all conscious and subconscious aspects are combined.

According to the object of our research there are language, speech and active approaches. In language approach the educational process is oriented to the studying language as a system. If at the lesson the speech approach is used, students are asked to express their thoughts without preparation. The focus of the active approach is on student's speech, which is caused by the situation and fulfilled by means of language system.

According to the methods of teaching there are only two approaches:

- direct or intuitive approach - the language is studied in the process of communication and intuitive understanding of language units, moreover the native language is not used;

- cognitive or conscious approach students fully understand language units and are able to explain the reason of their use, native language is used.

Having studied the main approaches to forming communicative culture we have identified the absence of special approach to training future interpreters. Considering the main goals and objectives of forming interpreter's communicative culture, we believe that in the process of professional interpreters' training it is worthwhile using integrated approach to forming future translators' communicative culture. This approach will naturally combine certain features of active, profession-oriented, competence, and cultural approaches as they are aimed at forming skills and abilities necessary for successful work of an interpreter. Thus we offer to study each of the above mentioned approaches to forming interpreter's communicative culture in more details.

Active approach to future interpreter's training is realized by means of intensive teaching methods (rolegames). In this case students can study phonetic, lexical and grammatical rules in the process of a real-life use. At 
the lesson the student's work is organized in a way that forces them to use a particular language material to reach a stated communicative purpose. Besides, an imaginary real-life situation helps students to interact more effectively, while rivalry caused by the rules of the game stimulates their motivation. We have decided to identify the active approach as the first one after a survey conducted in 2016 among $3^{\text {rd }}$ year philology students at Alfred Nobel University, Dnipro. The results of the investigation have shown that $64 \%$ of students consider that absence of real-life communicative situations is the main reason for difficulties at the beginning of their professional life. Furthermore, most of the students consider that courses offering them role-games as a teaching method are the most effective.

Within the framework of the integrated approach we offer to consider requirements of students' future profession (feature of profession oriented approach). In the process of university education it is of vital importance to make sure, that students could realize the modern requirements of the chosen profession. To be successful in both national and foreign labour markets, graduates have to realize how the real work is done. Students can understand the main peculiarities of their future profession due to the meetings with representatives of business, participation in workshops as well as internships. All these teaching methods could give the students an opportunity to see how the system works and to realize how they can use particular skills and knowledge, obtained in the process of university education. Our teaching experience shows that those students, who have started their professional work while studying at the university are motivated better and aimed at positive result because they fully realize practical application of theoretical knowledge in real life.

We believe that the main goal of integrated approach should be not the process of education, but its results (feature of competence approach). This idea results in the shift of priorities - the main purpose of education should not be accumulation of knowledge, but forming and development of student's ability to act, using the previous experience of successful interpretation in the specific situation. Such approach ensures that a graduate is ready to render his professional services effectively.

Translator's professional work involves deep interrelation between language and native speakers' culture. Integrated approach to forming future interpreter's communicative culture has in its basis an idea that culture is a goal, and the language is an educational tool (feature of cultural approach). Such shift of interests took place in 19801990. In that period at foreign language lessons students were taught not only language as it is, but also culture of the country it originated from. This feature of integrated approach presumes including the following courses curriculum: culture studies, history of the language, basics of psychology etc. Moreover we offer to use two tendencies for interpretation of language and culture facts: 1) from fact of language to the facts of culture; 2) from facts of culture to the facts of language. Such a comprehensive training of future interpreters will let them realize cultural peculiarities of representatives from different countries and consider them while conducting negotiations or rendering translation services.
In the integrated approach student as a subject of education process is a central figure, moreover the system of education presumes full understanding and consideration of individual psychological, age and national peculiarities of the students as well as their interests. Thus, we believe that integrated the approach would be the most beneficial for forming future interpreter's communicative culture in the process of their university education.

We believe that for successful implementation of the integrated approach the most effective would be the use of interactive methods of teaching, namely game technology. Using role-games as a teaching tool is becoming increasingly popular among trainers both in Ukraine and abroad. It can be explained by high level of motivation and thus results in the groups which faced not only traditional, but also interactive teaching methods were substantially better. According to D. Green and C. Blaszczynski the main features of a game as a teaching method obtains, are motivation, lack of stress and individual student's work [3]. A role-game in future interpreter's training increases motivation, stimulates brainstorming activity, enables students express their natural behaviour thus improving their comprehension abilities. It is a useful pedagogical tool since it lets students feel and act as if in a real-life situation similar to the situations of their future professional environment.

The essence of a role-game itself defines its primary goal - to develop and improve student's professional competence. After defining the topic of the game, its goal may be altered, it can be oriented to particular aspects of students' future professional work, thus forcing students to solve particular professional tasks. Another favourable aspect of a business game as a teaching tool is its correspondence to the course topic. With its help the students are given a chance to practice in using all obtained lexical and grammatical material on a given topic.

We would like to offer a role-game "Telephone negotiations" which is designed for a $3^{\text {rd }}$ year Philology students studying Business English course. The majority of students and graduates believe that the main problem occurring while conducting phone negotiations is the lack of actual "live contact" with an interlocutor. This is explained by the fact that in the process of their professional training students usually translate information that comes either from the teacher or from their colleagues. In this case a young translator pays huge attention to the speaker's mimics, using it as a hint to acquiring as much information as possible.

It is worth mentioning that teaching telephone communication is an important aspect of training future interpreters, thus we are offering a non-traditional approach to presenting this information.

A role-game as a teaching tool has three stages: preparation, active and analytical stages. The trainer participates in such a game at the preparation and analytical stages when the students receive instructions and rules, as well as at the time of final analysis of the game results. As a preparation for the game students are explained that it is necessary to avoid neutral phrases ("hello", "yes") while answering a phone call, instead it is advisable to state the name of the company, organisation or department. In the form of instruction, the trainer specifies general norms of business etiquette. Moreover before the game a group 
receives the list of phrases that should be avoided, namely "I do not know", "We cannot do this", "You have to" etc. Before the game students are offered to make up a list of questions for telephone negotiations, they are also reminded that telephone communication has to be short and precise.

After receiving instructions and finishing preparation at home, follows the second stage of the role-game active. There are two modes for this game. The first one is suitable for groups with average knowledge, as it doesn't have any extra complications. The trainer divides students in groups of three people each. This way each group will have the roles of "Translator", "Foreigner", and "Native Businessmen". All participants know what information they have to obtain and what information they have to transmit, thus they are conducting telephone communication according to the stated tasks.

The second mode was developed on the basis of students' feedback as to the process and expected results of their education. Graduates and students, who provide the service of telephone communication interpretation have specified that a lot of problems are caused by poor signal and therefore their inability to anticipate what an interlocutor is likely to say. Thus the second mode of this rolegame involves extra complications and is suitable for advanced groups. While students are conducting translation of an imaginary telephone conversation, the trainer turns on a player that produces various sounds (music, street traffic, people's voices etc), furthermore the trainer may walk among students and ask questions thus distracting them. Students are explained that this environment is similar to real-life working conditions, and this type of training will make them more competitive in the labour market.

At the third analytical stage the trainer assesses students' work, gives comments, answers questions, advises how to improve the results and asks students for a feedback.

Our experience shows that role-games are most effectively used at the final stage of studying a course or topic within a course. Only after a substantial theoretical work and learning vocabulary and grammar on a given topic students will be able to participate in a game, efficiently and fluently communicate with their partners.

We also share G. McSharry and S. Jones's opinions as to the step by step preparation for the role game [7]. At the initial stage students learn the necessary vocabulary themselves, using vocabulary and textbooks if necessary. At the beginning of studying some topic it is extremely important to inform students that at the end of work with this topic they will participate in a role-game, thus helping students to concentrate on particular aspects of their education. At the second stage the trainer creates micro situations which are parts of a future role-game. At this stage students can practice particular lexical and grammatical units, which will help them to express their opinion on a discussed problem. At the last stage students work with language units which correspond the best to the topic of the game.

Considering the above mentioned, we can say that the role-game as a pedagogical tool for forming future interpreter's communicative culture is extremely useful. Preparing the lesson with game elements requires from both a trainer and a student an extra effort, but practical experience shows that such activities increase productivity, motivate students and train them for future real-life translation in their professional career.

Conclusions. Modern educational process of future interpreter's professional training is believed to be complex and integrated. A trainer has to consider the most up-todate requirements of labour market, students' individual features and other aspects while developing scope of the lesson. A more beneficial educational process, better outcomes and achievement of pedagogical goals can be reached using the integrated approach as well as interactive teaching methods. With the help of authentic video materials which stimulate competition and enhance communication process, students can face their future professional environment within the framework of the lesson. The above-mentioned approach will make graduates more competitive in the global world market.

\section{REFERENCE}

1. Encyclopaedic sociology dictionary / Editor G.V. Osipova. M.: ISPI RAN, 1995. $-676 \mathrm{p}$.

2. Green, D., \& Blaszczynski, C. Effective strategies and activities for developing soft skills. // Journal of Applied Research for Business Instruction, 10(2). 2012.

3. Herskovits M. Cultural Anthropology / M. Herskovits. - N.Y., 1985. - $351 \mathrm{p}$

4. How Culture Controls Communication by Carol Kinsey Goman. Available at: http://www.forbes.com/sites/carolkinseygoman, accessed: 1306-2016

5. Katkova V.P. Forming communicative skills for future organization managers in extra curriculum activities. Lugans'k, 2013. $-229 \mathrm{p}$.

6. Lihacheva ZH.V. (1) Forming business communication skills while teaching the English language // Omskij nauchnyj vestnik. - 2014. - №3 (129). - P. 184-186.

7. McSharry, G., \& Jones, S. Role-play in science teaching and learning. // School Science Review. 2000. - P. 73-82.

8. Mitrova N.O. Forming communicative culture for university students in the process of their socio-cultural activities. Adygejsk State University: Majkop, 2006. - 27 p.

9. Nikolajeva S.Yu. (editor) Methodology of teaching foreign languages and cultures: theory and practice. Kyiv: Lenvit, 2013. $-590 \mathrm{p}$.

10. Philosophic dictionary $4^{\text {th }}$ ed. / Editor I.T. Frolova. - M.: Polizdat, 1981. $-445 \mathrm{p}$.

11. Sumner W., Keller A. The science of society. - New Heaven, 1927. - P.46-47.

12. Volkova N.P. Professional pedagogical communication: theory, technology, practice [Monography]. Dnipropetrovsk National University, 2005. - 304 p. 